\title{
Overview of Tigecycline and Its Role in the Era of Antibiotic Resistance
}

\author{
Flávia Rossi, Denise Andreazzi
}

University of São Paulo, LIM 03; São Paulo, SP, Brazil

\begin{abstract}
The increasing antimicrobial resistance found in the many clinically important species of bacteria that commonly cause serious and life-threatening diseases presents a difficult challenge for clinicians, especially when an appropriate initial therapy must be chosen. New antibiotics are urgently needed to address the formidable issues associated with infections caused by vancomycin-resistant enterococci (VRE), methicillin-resistant Staphylococcus aureus (MRSA), penicillin-resistant Streptococcus pneumoniae and multidrug-resistant Gram-negative bacteria. The need for new antibiotics that effectively resist antimicrobial mechanisms of resistance has become paramount. Tigecycline is a new antimicrobial agent; it is the first in a new class of antibiotics, the glycylcyclines, with properties conferring the ability to overcome many common resistance mechanisms, thus allowing the use of tigecycline for many serious and life-threatening infections for which the use of other antibiotics is no longer appropriate. Tigecycline is a novel expanded spectrum antibiotic that appears poised to meet the latest bacterial challenges facing clinicians, including the serious and life-threatening infections caused by highly resistant bacteria. Tigecycline, moreover, appears to hold promise as a new, versatile antibiotic that can be chosen for empirical therapy, even as a single agent, for initial therapy of many clinically important infections.
\end{abstract}

Key Words: Tigecycline, antibiotic resistance, antimicrobial mechanisms.

Changing and worsening trends of antimicrobial resistance among bacteria that commonly are responsible for serious infections present difficult challenges for clinicians; there is a need for newer and more powerful agents, especially for empiric therapy of seriously ill patients. The effectiveness of currently available antibiotics is decreasing due to the increasing number of resistant strains causing infections. New and novel antimicrobial agents are urgently needed to meet the challenge posed by the emergence of multidrug-resistant microorganisms. Moreover, the emergence of clinical resistance to previously active antibacterial agents among many clinically significant bacterial species has had a significant impact on empiric therapy choices available to the prescribing clinician [1-5].

Recently, much data has been published that suggests that antimicrobial resistance among pathogenic bacteria is leading to worsening of patient outcomes, including increased rates of mortality in both Gram-negative and Grampositive bacterial infections. In a recent retrospective, observational cohort study of outcomes in Enterobacter bacteremia, it was reported that the 30-day mortality rate of patients infected with resistant organisms was significantly Received on 02 February 2006; revised 13 June 2006.

Address for correspondence: Dr. Flávia Rossi, M.D., PhD Microbiology Laboratory Director. Hospital das Clínicas da Faculdade de Medicina*. University of São Paulo, LIM03 Rua Lee de Forest 32, São Paulo, São Paulo, Brazil. Zip code: 04576120. Phone: 55-11-5505-2480. Fax: 55-11-3758-0457 E-mail: ffrossi@attglobal.net.

*Hospital das Clínicas FMUSP is the Brazilian site for Tigecycline "in vitro" project denominated TEST.

The Brazilian Journal of Infectious Diseases 2006;10(3):203-216. (C) 2006 by The Brazilian Journal of Infectious Diseases and Contexto Publishing. All rights reserved. greater than for patients infected with susceptible bacteria (33.7\% versus $18.6 \% ; p=0.021)$. The authors concluded that broad-spectrum cephalosporin resistance negatively affects patient outcomes in those afflicted with Enterobacter bacteremia, especially in those patients without a discernible primary site of infection and in those with septic shock [6]. In a study of hospital-acquired Staphylococcus aureus bacteremia, a strong statistical trend towards death due to nosocomial methicillin-resistant Staphylococcus aureus infection and bacteremia, when compared with infections due to methicillin-susceptible Staphylococcus aureus, was reported [7].

In the hospital setting, when patients are diagnosed with a serious infection, bacterial cultures and multiple other tests are performed, and empiric antimicrobial agents are administered. Choice of empirical therapy in serious infections, such as bacteremia, is critical. It is important to choose an antibiotic regimen to which the pathogens are susceptible. In a study of bloodstream infections in an Israeli university hospital during 1988-1994, inappropriate empirical antibiotic therapy was associated with a significant increase in mortality in patients with bacteremia. A multivariable logistic regression analysis yielded an odds ratio of $1.6(95 \%$ confidence interval=1.3-1.9) for the contribution of inappropriate empirical therapy to mortality that was independent of other risk factors [8]. Another study documented the deleterious effects on clinical outcomes associated with delay of appropriate therapy for hospitalacquired Staphylococcus aureus bacteremia. In a multivariate analysis, a delay in initiating appropriate treatment was found to be an independent predictor of bacteremia-related mortality (odds ratio, 3.8; 95\% confidence interval $=1.3-11.0 ; \mathrm{p}=.01)$ and longer hospitalization (20.2 days versus 14.3 days; $p=.05$ ) [9]. 
The fundamental requirements of a desirable antibiotic that is to be used empirically for serious infections in which antibiotic-resistant organisms may be responsible, include high potency with proven clinical activity and safety, limited potential for the development of antimicrobial resistance to the agent, and low propensity for adverse events and drug interactions. Reasonable options for empiric therapy have been dwindling, largely due to the development and spread of resistance mechanisms among many genera of bacteria. Increasing rates of vancomycin-resistant enterococci, methicillin-resistant Staphylococcus aureus, penicillin-resistant Streptococcus pneumoniae and multidrug-resistant Gram-negative bacteria containing expanded spectrum beta-lactamases have severely limited the breadth of active antimicrobial agents that could be utilized in a medical institutional setting $[3,10]$. Also of great concern to practicing physicians is the development of vancomycin-resistant Staphylococcus aureus in the hospital setting and the increasing participation of methicillin-resistant Staphylococcus aureus as a community pathogen. The increase in the prevalence of these multidrug-resistant bacteria has led to increased usage of combination therapy, in which two or even three antimicrobial agents are commonly used in the initial treatment period, with the associated disadvantages of increased drug acquisition costs and administration, and increased risks of adverse drug reactions and interactions with other drugs administered to the patient $[11,12]$.

Tigecycline, (9-t-butylglycylamido-minocycline; GAR936, Wyeth Laboratories, Collegeville, PA), is a new glycylcycline that has been developed and is being studied in human clinical trials. In vitro testing with tigecycline has revealed potent antibacterial activity against a large number of disease-causing Gram-positive and Gram-negative aerobic bacteria, and anaerobes, including Staphylococcus aureus, Enterococcus species, Streptococcus pneumoniae, Hemophilus influenzae, Moraxella catarrhalis, Neisseria gonorrhoeae, and most Enterobacteriaceae and Bacteroides species [13].

Tigecycline has limited or no in vitro activity against Pseudomonas aeruginosa, and reduced activity against indole-positive Proteae and Proteus mirabilis has been reported $[14,15,16]$. Additionally, tigecycline exhibits robust activity against bacterial isolates resistant to other antibiotic classes, including beta-lactams and fluoroquinolones, while resisting deactivation by most of the known tetracycline resistance mechanisms found in clinically significant bacteria [17]. Tigecycline is being evaluated as monotherapy for serious infections in human clinical trials as a result of its microbiological, pharmacodynamic and pharmacokinetic properties $[18,19]$. Clinical trials comparing tigecycline to other antimicrobial agents are being performed in patients with complicated skin and skin-structure infections, intraabdominal infections and pneumonia [16,20,21].

\section{Tigecycline Chemistry and Mechanism of Action, and Overcoming Resistance Mechanisms}

The tetracycline class of antimicrobials inhibits bacterial growth by binding to the bacterial $30 \mathrm{~S}$ ribosomal subunit, which blocks entry of amino-acyl transfer RNA molecules into the A site of the ribosome. The elongation of peptide chains is prevented because there is no more incorporation of amino acid residues into the peptide chains. This results in overall inhibition of protein synthesis. Tetracyclines are, for the most part, bacteriostatic [19].

Glycylcyclines are a novel group of antimicrobial agents. These agents retain a central four-ring carbocyclic skeleton of the tetracycline class that is crucial for antimicrobial activity. Modifications include substitution of an N-alkyl-glycylamido group on the D ring at the 9 th position that confers a broader spectrum of activity; this modification gives this antibiotic the ability to evade tetracycline resistance mechanisms (Figure 1). Tigecycline has a 9-t-butyl-glycylamido side chain on the central skeleton (Figure 2). It has a molecular weight of 585.65 Daltons and its chemical formula is $\mathrm{C}_{29} \mathrm{H}_{39} \mathrm{~N}_{5} \mathrm{O}_{8}[16,18]$.

Active efflux of drugs from inside the bacterial cell and ribosomal protection are the two main mechanisms of bacterial resistance to tetracyclines $[22,23]$. The spread of resistance to tetracyclines by bacteria occurs through the acquisition of specific resistance genes, which are found in plasmids, conjugative transposons and integrons [19]. Tigecycline most likely overcomes these tetracycline resistance mechanisms due to steric hindrance by a large substituent at position 9 [24].

Experiments conducted with dimethylsulphate modification of tetracycline and tigecycline binding sites, mutational analysis of $16 \mathrm{~S}$ rRNA and tigecycline modeling at a previously identified tetracycline-binding site in the $30 \mathrm{~S}$ ribosomal subunit support the importance of steric hindrance [17].

Tigecycline activity has been studied in Escherichia coli KAM3 (acrB) strains containing plasmids encoding various different tetracycline-specific efflux transporter genes [tet(B), tet $(\mathrm{C})$, and tet $(\mathrm{K})]$. In addition, the effects of multidrug transporter genes, acrAB, acrEF, and bcr, have been examined. These studies revealed that tigecycline exhibited potent in vitro activity against all three of the Tet-expressing, tetracycline-resistant strains. Minimum inhibitory concentrations (MICs) for the mutant strains were the same as those for the original strains. At a low concentration of tigecycline, it appears that the agent is not taken up by the Tet efflux transporter. This likely is the reason for the potent antimicrobial activity of tigecycline. The studies also suggested that tigecycline is a substrate of AcrAB and AcrEF, which have been reported to be resistance-modulationdivision-type multicomponent efflux transporters. Tigecycline MICs for organisms containing these multidrug efflux proteins increased fourfold [25]. 
Figure 1. Basic structure of the glycylcyclines<smiles>CN(C)C1C(O)=C(C(N)=O)C(=O)C2(O)C(O)=C3C(=O)c4c(ccc([Tl])c4O)CC3CC12</smiles>

Figure 2. Structure of tigecycline<smiles>CN(C)c1cc(NC(=O)CNC(C)(C)C)c(O)c2c1CC1CC3C(N(C)C)C(O)=C(C(N)=O)C(=O)C3(O)C(O)=C1C2=O</smiles>

Table 1. In vitro activity of tigecycline against aerobic Gram-positive organisms

\begin{tabular}{|c|c|c|c|}
\hline Organism & $\begin{array}{c}\text { MIC Range } \\
(\mu \mathrm{g} / \mathrm{mL})\end{array}$ & $\begin{array}{c}\text { MIC }_{50} \text { Range } \\
(\mu \mathrm{g} / \mathrm{mL})\end{array}$ & $\begin{array}{c}\text { MIC }_{90} \text { Range } \\
(\mu \mathrm{g} / \mathrm{mL})\end{array}$ \\
\hline Staphylococcus aureus & $\leq 0.02-2$ & $0.06-0.5$ & $0.125-1$ \\
\hline S. aureus $\left(\mathrm{OXA}^{\mathrm{S}}\right)$ & $0.06-1$ & $\leq 0.13-0.5$ & $0.25-0.5$ \\
\hline S. aureus $\left(\mathrm{OXA}^{\mathrm{R}}\right)$ & $\leq 0.06-2$ & $\leq 0.13-0.5$ & $0.25-1$ \\
\hline S. aureus $\left(\mathrm{VAN}^{\mathrm{I}}\right)$ & $0.06-2$ & 0.25 & 0.5 \\
\hline CN staphylococci & $\leq 0.03-2$ & $0.06-1$ & $0.25-1$ \\
\hline CN staphylococci $\left(\mathrm{OXA}^{\mathrm{S}}\right)$ & $\leq 0.03-1$ & $0.25-0.5$ & $0.25-1$ \\
\hline $\mathrm{CN}$ staphylococci $\left(\mathrm{OXA}^{\mathrm{R}}\right)$ & $\leq 0.03-2$ & $0.5-1$ & $0.25-1$ \\
\hline Enterococcus species & $\leq 0.02-2$ & $0.03-0.25$ & $0.06-0.5$ \\
\hline E. faecalis & $\leq 0.02-2$ & $0.13-0.25$ & $0.13-0.5$ \\
\hline E. faecalis $\left(\mathrm{VAN}^{\mathrm{R}}\right)$ & $\leq 0.03-0.5$ & 0.13 & $0.13-0.5$ \\
\hline E. faecium & $\leq 0.03-0.5$ & $0.06-0.25$ & $0.13-0.25$ \\
\hline E. faecium $\left(\mathrm{VAN}^{\mathrm{R}}\right)$ & $\leq 0.03-0.5$ & $0.06-0.13$ & 0.13 \\
\hline E. avium & $0.06-0.13$ & 0.06 & 0.06 \\
\hline E. casseliflavus & $\leq 0.03-0.5$ & $0.13-0.25$ & $0.13-0.25$ \\
\hline E. fallinarum & $0.06-2$ & 0.13 & $0.13-0.25$ \\
\hline E. raffinosus & $0.06-0.5$ & 0.06 & 0.13 \\
\hline Streptococcus pneumoniae & $\leq 0.01-1$ & $\leq 0.02-0.25$ & $\leq 0.02-0.5$ \\
\hline S. pneumoniae $\left(\mathrm{PEN}^{\mathrm{S}}\right)$ & $\leq 0.02-0.5$ & $0.03-0.25$ & $0.13-0.25$ \\
\hline S. pneumoniae $\left(\mathrm{PEN}^{\mathrm{I}}\right)$ & $\leq 0.02-1$ & $0.03-0.25$ & $0.06-0.5$ \\
\hline S. pneumoniae (PENR) & $\leq 0.02-1$ & $0.06-0.25$ & $0.13-0.25$ \\
\hline S. pneumoniae $\left(\mathrm{TET}^{\mathrm{S}}\right)$ & $0.01-0.13$ & 0.03 & 0.03 \\
\hline S. pneumoniae $\left(\mathrm{TET}^{\mathrm{R}}\right)$ & $0.02-0.5$ & 0.03 & 0.03 \\
\hline Group A streptococci & $\leq 0.02-0.5$ & $0.06-0.13$ & $0.06-0.25$ \\
\hline Group B streptococci & $0.03-0.5$ & $0.06-0.13$ & $0.06-0.25$ \\
\hline Viridans streptococci & $0.01-2$ & $\leq 0.02-0.06$ & $0.03-0.5$ \\
\hline Viridans streptococci $\left(\mathrm{PEN}^{\mathrm{S}}\right)$ & $0.03-0.25$ & 0.06 & 0.25 \\
\hline Viridans streptococci $\left(\mathrm{PEN}^{\mathrm{R}}\right)$ & $0.02-0.13$ & 0.03 & 0.06 \\
\hline Viridans streptococci $\left(\mathrm{TET}^{\mathrm{S}}\right)$ & $0.02-0.06$ & 0.03 & 0.06 \\
\hline Viridans streptococci $\left(\mathrm{TET}^{\mathrm{R}}\right)$ & $0.01-0.5$ & 0.06 & 0.13 \\
\hline
\end{tabular}

$\overline{\mathrm{CN}}$, coagulase negative; I, intermediate; OXA, oxacillin; PEN, penicillin; R, resistant; S, susceptible; TET, tetracycline; VAN, vancomycin.

In addition, it has been difficult to experimentally generate significant mutant bacteria exhibiting resistance to tigecycline. Among those mutants that have been generated, only marginal changes in susceptibility to tigecycline have been noted. Consequently, it has been surmised that clinically significant tigecycline resistance will not easily arise and will require more than trivial mutations in known resistance genes [24].

\section{In vitro Activity of Tigecycline}

The spectrum of in vitro activity of tigecycline is displayed in Table 1 (aerobic Gram-positive bacteria), Table 2 (aerobic Gram-negative bacteria), Table 3 (anaerobes) and Table 4 (atypical organisms) [16]. 
Table 2. In vitro activity of tigecycline against aerobic Gram-negative organisms

\begin{tabular}{|c|c|c|c|}
\hline Organism & $\begin{array}{c}\text { MIC Range } \\
(\mu \mathrm{g} / \mathrm{mL})\end{array}$ & $\begin{array}{c}\text { MIC }_{50} \text { Range } \\
(\mu \mathrm{g} / \mathrm{mL})\end{array}$ & $\begin{array}{c}\text { MIC }_{90} \text { Range } \\
(\mu \mathrm{g} / \mathrm{mL})\end{array}$ \\
\hline \multicolumn{4}{|l|}{ Enterobacteriacae } \\
\hline Escherichia coli & $0.06-2$ & $0.13-0.5$ & $0.25-1$ \\
\hline E. coli (non-ESBL) & $0.06-2$ & $0.13-0.5$ & $0.25-1$ \\
\hline E. coli (ESBL) & $0.06-2$ & $0.13-0.25$ & $0.5-1$ \\
\hline E. coli $\left(\mathrm{CIP}^{\mathrm{S}}\right)$ & $0.5-2$ & 1 & 1 \\
\hline E. coli $\left(\mathrm{CIP}^{\mathrm{R}}\right)$ & $0.5-2$ & 1 & 1 \\
\hline Klebsiella pneumoniae & $0.06-8$ & $0.25-1$ & $1-2$ \\
\hline K. pneumoniae (non-ESBL) & $0.06-4$ & $0.25-1$ & $1-2$ \\
\hline K. pneumoniae (ESBL) & $0.06-8$ & $0.25-1$ & $1-2$ \\
\hline Klebsiella oxytoca & $0.5-2$ & $0.5-1$ & 1 \\
\hline Morganella morganii & $1-8$ & $2-4$ & 4 \\
\hline Proteus mirabilis & $1-8$ & 4 & 8 \\
\hline Proteus vulgaris & $0.13-16$ & 4 & 4 \\
\hline Providencia species & $4-8$ & 4 & 8 \\
\hline Shigella species & $0.13-0.5$ & 0.25 & 0.5 \\
\hline Salmonella species & $0.25-2$ & 1 & 1 \\
\hline Citrobacter species & $0.25-16$ & $0.5-1$ & $0.5-2$ \\
\hline C. freundii & $0.25-16$ & $0.5-1$ & 2 \\
\hline Enterobacter species & $0.25-8$ & 1 & $1-2$ \\
\hline E. cloacae & $0.25-4$ & 1 & 2 \\
\hline E. aerogenes & $0.25-8$ & 1 & 1 \\
\hline Serratia marcescens & $0.5-8$ & $2-4$ & $2-4$ \\
\hline \multicolumn{4}{|l|}{ Non-Enterobacteriacae } \\
\hline Stenotrophomonas maltophilia & $0.25-8$ & $0.5-2$ & $2-4$ \\
\hline Pseudomonas aeruginosa & $0.5-32$ & $8->16$ & $16-32$ \\
\hline Acinetobacter species & $\leq 0.03-16$ & $0.25-2$ & $0.5-8$ \\
\hline A. baumannii & $0.03-16$ & $0.5-2$ & $2-8$ \\
\hline Burkholderia cepacia & $0.5-64$ & $2-4$ & $4-32$ \\
\hline \multicolumn{4}{|c|}{ Gram-Negative Respiratory Pathogens } \\
\hline Haemophilus influenzae & $\leq 0.13-4$ & $0.25-1$ & $0.5-2$ \\
\hline Moraxella species & $\leq 0.03-0.25$ & $0.06-0.13$ & $0.13-0.25$ \\
\hline M. catarrhalis & $\leq 0.03-2$ & $0.06-0.13$ & $0.13-0.5$ \\
\hline \multicolumn{4}{|l|}{ Other Gram-Negative Aerobes } \\
\hline Neisseria gonorrhoeae & $\leq 0.02-1$ & $0.06-0.5$ & $0.13-1$ \\
\hline N. gonorrhoeae $\left(\mathrm{TET}^{\mathrm{S}}\right)$ & $\leq 0.02-0.25$ & 0.06 & 0.13 \\
\hline N. gonorrhoeae $\left(\mathrm{TET}^{\mathrm{I}}\right)$ & $0.06-0.25$ & 0.13 & 0.25 \\
\hline N. gonorrhoeae $\left(\mathrm{TET}^{\mathrm{R}}\right)$ & $0.06-1$ & 0.25 & 0.5 \\
\hline Eikenella corrodens & $\leq 0.06-4$ & 0.5 & 2 \\
\hline
\end{tabular}

CIP, ciprofloxacin; ESBL, extended-spectrum beta-lactamase; I, intermediate; MIN, minocycline; R, resistant; S, susceptible; TET, tetracycline.

\section{Reported Activity Against Large Collections of Multiple Species of Bacteria}

The in vitro activity of tigecycline was evaluated with a collection of 11,859 bacterial isolates recovered from patients in the years 2000 and 2002. These patients were treated in 29 countries, and they were diagnosed with community-acquired respiratory tract infections (3,317 Gram-positive and Gramnegative bacterial strains), and skin and soft tissue infections (8,542 Gram-positive strains). Tigecycline's potency was demonstrated against oxacillin-susceptible and oxacillin-resistant Staphylococcus aureus (5,077 strains, $\left.\mathrm{MIC}_{90}=0.5 \mu \mathrm{g} / \mathrm{mL}\right)$, coagulase-negative staphylococci (1,432 strains, $\mathrm{MIC}_{90}=0.5 \mu \mathrm{g} /$ $\mathrm{mL}$ ), penicillin-susceptible and penicillin-resistant Streptococcus 
Table 3. In vitro activity of tigecycline against anaerobic organisms

\begin{tabular}{|c|c|c|c|}
\hline Organism & $\begin{array}{c}\text { MIC range } \\
(\mu \mathrm{g} / \mathrm{mL})\end{array}$ & $\begin{array}{c}\text { MIC }_{50} \text { range } \\
(\mu \mathrm{g} / \mathrm{mL})\end{array}$ & $\begin{array}{c}\text { MIC }_{90} \text { range } \\
(\mu \mathrm{g} / \mathrm{mL})\end{array}$ \\
\hline Bacteriodes fragilis & $0.5-8$ & 2 & 2 \\
\hline Bacteriodes fragilis group & $0.02-2$ & $0.13-0.5$ & $0.13-2$ \\
\hline Clostridium perfringens & $0.03-4$ & $0.03-0.5$ & $0.25-1$ \\
\hline Clostridium difficile & $\leq 0.02-0.25$ & $0.03-0.13$ & $0.03-0.13$ \\
\hline Proprionibacterium acnes & $0.03-0.13$ & 0.03 & 0.06 \\
\hline Peptostreptococcus species & $\leq 0.02-0.5$ & $0.03-0.06$ & $0.03-0.25$ \\
\hline Fusobacterium species & $\leq 0.02-0.25$ & $0.02-0.06$ & 0.06 \\
\hline Prevotella species & $0.02-1$ & $0.03-0.5$ & $0.06-1$ \\
\hline Porphyromonas species & $\leq 0.02-0.13$ & $0.03-0.06$ & 0.06 \\
\hline
\end{tabular}

Table 4. In vitro activity of tigecycline against atypical organisms

\begin{tabular}{|c|c|c|c|}
\hline Organism & $\begin{array}{c}\text { MIC range } \\
(\mu \mathrm{g} / \mathrm{mL})\end{array}$ & $\begin{array}{c}\text { MIC }_{50} \text { range } \\
(\mu \mathrm{g} / \mathrm{mL})\end{array}$ & $\begin{array}{c}\text { MIC }_{90} \text { range } \\
(\mu \mathrm{g} / \mathrm{mL})\end{array}$ \\
\hline \multicolumn{4}{|l|}{ Mycobacterium abscessus } \\
\hline TET $^{\mathrm{S}}$ & $\leq 0.06-1$ & $\leq 0.13$ & 0.25 \\
\hline $\mathrm{TET}^{\mathrm{R}}$ & $\leq 0.06-1$ & $\leq 0.13$ & 0.25 \\
\hline \multicolumn{4}{|l|}{ Mycobacterium chelonae } \\
\hline TET $^{\mathrm{S}}$ & $\leq 0.25$ & $\leq 0.06$ & $\leq 0.13$ \\
\hline $\mathrm{TET}^{\mathrm{R}}$ & $\leq 0.25$ & $\leq 0.06$ & $\leq 0.13$ \\
\hline \multicolumn{4}{|l|}{ Mycobacterium fortuitum group } \\
\hline TET $^{\mathrm{S}}$ & $\leq 0.25$ & $\leq 0.06$ & $=0.13$ \\
\hline $\mathrm{TET}^{\mathrm{R}}$ & $\leq 0.25$ & $\leq 0.06$ & $=0.13$ \\
\hline Mycobacterium avium complex & $32->32$ & $>32$ & $>32$ \\
\hline Mycobacterium lentiflavum & $32->32$ & $>32$ & $>32$ \\
\hline Mycobacterium marinum & $0.19-24$ & $2-16$ & $3-16$ \\
\hline Mycobacterium kansasii & 8-32 & 16 & 32 \\
\hline Chlamydophyla pneumoniae & $0.13-0.25$ & 0.13 & 0.13 \\
\hline \multicolumn{4}{|l|}{ Mycoplasma hominis } \\
\hline TET $^{\mathrm{S}}$ & $0.13-0.5$ & 0.25 & 0.5 \\
\hline $\mathrm{TET}^{\mathrm{R}}$ & $0.13-0.5$ & 0.25 & 0.5 \\
\hline Mycoplasma pneumoniae & $0.06-0.25$ & 0.13 & 0.25 \\
\hline Ureaplasma urealyticum & $1-16$ & 4 & 8 \\
\hline
\end{tabular}

$\mathrm{R}$, resistant; S, susceptible; TET, tetracycline.

pneumoniae $\left(1,585\right.$ strains, $\left.\mathrm{MIC}_{90} \leq 0.25 \mu \mathrm{g} / \mathrm{mL}\right)$, viridans group streptococci (212 strains, $\mathrm{MIC}_{90} \leq 0.25-0.5 \mu \mathrm{g} / \mathrm{mL}$ ), vancomycinsusceptible and vancomycin-resistant enterococci (1,416 strains, $\mathrm{MIC}_{90}=0.25-0.5 \mu \mathrm{g} / \mathrm{mL}$ ), beta-hemolytic streptococci (405 strains, $\mathrm{MIC}_{90} \leq 0.25 \mu \mathrm{g} / \mathrm{mL}$ ), beta-lactamase positive and negative Haemophilus influenzae (1,220 strains, $\left.\mathrm{MIC}_{90}=1 \mu \mathrm{g} / \mathrm{mL}\right)$, Moraxella catarrhalis (495 strains, $\mathrm{MIC}_{90}=0.25 \mu \mathrm{g} / \mathrm{mL}$ ), and Neisseria meningitidis ( 17 strains, $\mathrm{MIC}_{90} \leq 0.12 \mu \mathrm{g} / \mathrm{mL}$ ). All strains were inhibited with $\leq 2 \mu \mathrm{g} / \mathrm{mL}$ of tigecycline, with no difference noted between tetracycline-resistant versus doxycycline-resistant bacteria. The authors concluded that tigecycline appears to be an attractive candidate for further clinical development and potential use in serious community-acquired respiratory tract infections and for skin and soft tissue infections [26].
Five thousand ninety-two blood culture isolates were collected by 29 laboratories that were located throughout the United Kingdom and Ireland in 2001 and 2002. Oxacillin resistance was found in $42 \%$ and $76 \%$ of Staphylococcus aureus and coagulase-negative staphylococci, respectively. Overall, in this study of bacteremias, tigecycline MICs were reportedly low for Gram-positive bacteria, including a large number of Enterococcus faecium strains. In vitro activity was also good for most of the tested Enterobacteriaceae, with exceptions for Proteeae and Enterobacter species [27].

In another study with 1,087 bacterial strains from 12 Spanish medical centers, the in vitro activity of tigecycline against 14 bacterial species was compared to those of other antibiotics. Tigecycline exhibited potent activity against a wide spectrum 
of bacteria, including methicillin-resistant Staphylococcus aureus, coagulase-negative staphylococci, penicillin-resistant Streptococcus pneumoniae, Enterococcus faecium, Acinetobacter baumannii, and Stenotrophomonas maltophilia. One hundred and two Streptococcus pneumoniae isolates were evaluated in this study, of which $54.9 \%$ were resistant to erythromycin, $62.7 \%$ tested intermediate to penicillin and $37.3 \%$ were highly resistant to penicillin. Tigecycline was highly active against the pneumococcal strains, regardless of resistance or susceptibility to beta-lactams or macrolides, with tigecycline MICs ranging from $\leq 0.06$ to $0.125 \mu \mathrm{g} / \mathrm{mL}$. For the staphylococci, tigecycline MICs were $\leq 0.5 \mu \mathrm{g} / \mathrm{mL}$ for all strains. Tigecycline was also found to be equally effective against Enterococcus faecium and Enterococcus faecalis. Tigecycline activity against vancomycin-resistant enterococci could not be evaluated, as no vancomycin-resistant isolates were found in this collection [28].

Additionally, in this Spanish study, tigecycline $\mathrm{MIC}_{90} \mathrm{~s}$ for all of the Enterobacteriaceae isolates ranged from 0.5 to 2 $\mu \mathrm{g} / \mathrm{mL}$. Tigecycline was the most active antibiotic after polymixin B, when tested against Acinetobacter baumannii, with greater than $90 \%$ of strains being inhibited by $8 \mu \mathrm{g} / \mathrm{mL}$ of tigecycline. In this collection of Acinetobacter baumannii strains, imipenem resistance was found in $28.1 \%$ of the isolates. At $4 \mu \mathrm{g} / \mathrm{mL}$, tigecycline inhibited $86.7 \%$ of all the anaerobes, and its activity was uniform among the different species. The species that were tested included Bacteroides fragilis, other members of the Bacteroides fragilis group and toxigenic Clostridium difficile. Against Clostridium difficile, tigecycline inhibited $92.7 \%$ of isolates at $0.125 \mu \mathrm{g} / \mathrm{mL}$, making tigecycline the most active of the agents tested, which included metronidazole [28].

Another study compared the activity of tigecycline to minocycline, doxycycline, tetracycline, moxifloxacin, penicillin $\mathrm{G}$, and erythromycin against bacterial isolates that were collected from infected human and animal bite wounds in humans. Two hundred and sixty-eight aerobic and 148 anaerobic strains of bacteria, including Pasteurella, Eikenella, Moraxella, Bergeyella, Neisseria, EF-4, Bacteroides, Prevotella, Porphyromonas, Fusobacterium, Staphylococcus, Streptococcus, Enterococcus, Corynebacterium, Propionibacterium, Peptostreptococcus, and Actinomyces species, were studied. Tigecycline $\mathrm{MIC}_{90} \mathrm{~S}$ were $\leq 0.25 \mu \mathrm{g} / \mathrm{mL}$ for all anaerobic species and almost all aerobic Gram-positive and Gram-negative strains, regardless of the presence of tetracycline-resistant strains. The exception was Eikenella corrodens, for which the $\mathrm{MIC}_{90}$ was $\leq 4 \mu \mathrm{g} / \mathrm{mL}$. In addition, erythromycin-resistant and moxifloxacin-resistant fusobacteria were well inhibited by tigecycline with a $\mathrm{MIC}_{90}$ of $0.06 \mu \mathrm{g} / \mathrm{mL}$ [29].

Tigecycline's in vitro activity has also been assessed with a broad spectrum of bloodstream isolates selected for their geographic diversity in the SENTRY surveillance program.
Tigecycline was tested against 604 strains of Gram-positive cocci bacteria, 98 strains of Klebsiella pneumoniae and 78 strains of Escherichia coli. Ninety-six of the Gram-negative bacteria produced extended-spectrum beta-lactamases, confirmed by testing with clavulanate. Tigecycline displayed potent activity against the Gram-positive bacteria, with MICs ranging from $\leq 0.015$ to $1 \mu \mathrm{g} / \mathrm{mL}$ and $\mathrm{MIC}_{90} \mathrm{~s}$ that ranged from $\leq$ $0.05 \mu \mathrm{g} / \mathrm{mL}$ for the pneumococci to $0.25 \mu \mathrm{g} / \mathrm{mL}$ for the staphylococci. Tigecycline's MICs for the 176 Gram-negative isolates ranged from $0.06-4 \mu \mathrm{g} / \mathrm{mL}$, with $\mathrm{MIC}_{90} \mathrm{~s}$ of $0.25-1 \mu \mathrm{g} /$ $\mathrm{mL}$. It was noted that the presence of extended-spectrum betalactamases had little effect on the in vitro activity of tigecycline. The authors of this study remarked that tigecycline displayed potent activity that was especially impressive against Grampositive cocci bacteria when compared to results obtained with vancomycin, linezolid or quinupristin/dalfopristin [13].

\section{Gram-positive bacteria}

The in vitro activity of tigecycline was compared to nine other agents, using a recently developed worldwide collection of 10,127 staphylococcal, streptococcal and enterococcal isolates. These isolates were collected from 93 medical centers located in 29 countries. All streptococci were inhibited by tigecycline at $2 \mu \mathrm{g} / \mathrm{mL}$ or less. Tigecycline also exhibited equal activity against oxacillin-susceptible and oxacillin-resistant Staphylococcus aureus and coagulase-negative staphylococci $\left(\mathrm{MIC}_{90}=0.5 \mu \mathrm{g} / \mathrm{mL}\right)$. Additionally, tigecycline was the most active antimicrobial agent when tested against vancomycin-susceptible and vancomycin-resistant enterococci. Tigecycline's potent activity was evident against all strains of Streptococcus pneumoniae, viridans group streptococci and beta-hemolytic streptococci $\left(\mathrm{MIC}_{90} \mathrm{~s} \leq 0.12\right.$ $\mu \mathrm{g} / \mathrm{mL}$ ). Tigecycline exhibited very potent and broad-spectrum activity against enterococci and streptococci [26].

Tigecycline's ability to inhibit vancomycin-resistant enterococci and staphylococci with diminished susceptibility to glycopeptides was evaluated with clinical isolates collected in Madrid, Spain, from 1998-2001. The vancomycin-resistant enterococci were Enterococcus faecalis $(\mathrm{n}=25)$, Enterococcus faecium $(\mathrm{n}=41)$, Enterococcus casseliflavus $(\mathrm{n}=21)$ and Enterococcus gallinarum $(\mathrm{n}=10)$. Twenty-eight of the isolates expressed the VanA phenotype, 38 expressed the VanB phenotype, and 31 expressed the VanC phenotype. Additionally, 54 strains of coagulase-negative staphylococci and six of Staphylococcus aureus isolates exhibiting reduced susceptibility to glycopeptides were also tested. All strains were inhibited by tigecycline at concentrations of from $\leq 0.03$ to $1 \mu \mathrm{g} / \mathrm{mL}$, regardless of resistance to tetracycline. Tigecycline testing revealed potent activity against glycopeptide-resistant enterococci, which included VanA, VanB and VanC phenotypes [30].

In a study of 602 North American isolates of methicillinsusceptible and methicillin-resistant Staphylococcus aureus, 
tigecycline MICs ranged from 0.06 to $1.0 \mu \mathrm{g} / \mathrm{mL}$. Tigecycline exhibited high activity with $\mathrm{MIC}_{50} \mathrm{~s}$ and $\mathrm{MIC}_{90} \mathrm{~s}$ of 0.12 and $0.25 \mu \mathrm{g} / \mathrm{mL}$ for methicillin-susceptible Staphylococcus aureus, and 0.25 and $0.5 \mu \mathrm{g} / \mathrm{mL}$ for methicillin-resistant Staphylococcus aureus, respectively [31]. In another trial with a clinical collection of 527 Gram-positive isolates from a Boston, Massachusetts hospital, tigecycline inhibited almost all of the strains at concentrations of $\leq 2 \mu \mathrm{g} / \mathrm{mL}$, regardless of resistance to other tetracyclines. The exception was two strains of JK diphtheroids, for which the MIC was $4 \mu \mathrm{g} / \mathrm{mL}$ [32].

In a French study, epidemiologically unrelated multidrugresistant strains of Staphylococcus aureus and Streptococcus pneumoniae were collected. Tigecycline exhibited very potent in vitro activity, with MICs ranging from 0.25 to $1 \mu \mathrm{g} / \mathrm{mL}$ for the 133 isolates of Staphylococcus aureus and 0.06 to $0.5 \mu \mathrm{g} /$ $\mathrm{mL}$ for the 105 Streptococcus pneumoniae isolates [33].

In a study made with 201 Streptococcus pneumoniae isolates, tigecycline exhibited very good activity, with MICs ranging from $\leq 0.016$ to $0.125 \mu \mathrm{g} / \mathrm{mL}$. Tigecycline was more active than tetracycline, minocycline or doxycycline. Moreover, against 11 of 12 strains, tigecycline was bactericidal [34]. In another study involving 25 Canadian medical centers, 6,991 unique patient isolates of Streptococcus pneumoniae were collected, and $20.2 \%$ of these isolates were reported to be penicillin nonsusceptible, with $14.6 \%$ being penicillin intermediate $(\mathrm{MIC}=0.12$ to $1 \mu \mathrm{g} / \mathrm{mL}$ ) and $5.6 \%$ being penicillinresistant ( $\mathrm{MIC} \geq 2 \mu \mathrm{g} / \mathrm{mL}$ ). Against these bacterial isolates, tigecycline had very good in vitro activity [35].

In a recent study, tigecycline activity was evaluated with 107

Streptococcus pyogenes and 98 Streptococcus agalactiae isolates, collected at the Hospital Clínico San Carlos in Madrid, Spain, from 1994 to 2001. Variable susceptibility to tetracycline and no activity of erythromycin were noted for these isolates. Tigecycline was very active against all the isolates tested, including those resistant to tetracycline, with an $\mathrm{MIC}_{90}=0.06$ $\mu \mathrm{g} / \mathrm{mL}$. All of the isolates were very susceptible to penicillin. Tigecycline was the most active after penicillin, and tigecycline exhibited more activity than minocycline, tetracycline, erythromycin, clindamycin and quinupristin-dalfopristin. No difference in the activity of tigecycline against tetracyclinesusceptible and tetracycline-resistant streptococcal isolates was noted; with tetracycline-resistant Streptococcus agalactiae and Streptococcus pyogenes isolates being inhibited by $\leq 0.25$ and $\leq 0.06 \mu \mathrm{g} / \mathrm{mL}$ of tigecycline, respectively. The authors concluded that the potent activity of tigecycline against all of the isolates, regardless of resistance to erythromycin or tetracycline, suggested that tigecycline could be considered as an alternative to penicillin for the treatment of infections caused by these organisms [36].

The in vitro activity of tigecycline was studied with 37 clinical isolates of vancomycin-resistant enterococci (including organisms carrying the VanA, VanB, VanC-1, and VanC-2/3 genes), 26 isolates of methicillin-resistant Staphylococcus aureus and 30 isolates of high-level penicillin-resistant Streptococcus pneumoniae. Tigecycline was highly active, with inhibition of growth of all isolates of vancomycin-resistant enterococci, methicillin-resistant Staphylococcus aureus and penicillin-resistant Streptococcus pneumoniae being noted with $\leq 1, \leq 2$, and $\leq 0.25 \mu \mathrm{g} / \mathrm{mL}$ of tigecycline, respectively. Time-kill experiments were also performed using vancomycinresistant enterococci, which did not show synergy or antagonism with tigecycline and quinupristin/dalfopristin [37]. In another study, the activity of tigecycline and daptomycin were studied against staphylococcal, enterococcal and streptococcal clinical isolates that were collected between 1990 and 1999 from various United States and Canadian medical centers. Tigecycline exhibited more in vitro activity than daptomycin, with $\mathrm{MIC}_{90} \mathrm{~s}$ from 0.12 to $1 \mu \mathrm{g} / \mathrm{mL}$ for tigecycline versus 0.5 to $16 \mu \mathrm{g} / \mathrm{mL}$ for daptomycin [38].

Tigecycline activity was studied alone and in combination with other antibiotics against multidrug-resistant strains of Enterococcus faecium and Staphylococcus aureus, consisting of two strains of vancomycin-resistant Enterococcus faecium, three glycopeptide-intermediately resistant Staphylococcus aureus strains and one methicillin-resistant Staphylococcus aureus strain. The activity of tigecycline was compared to that of vancomycin, gentamicin, rifampin, and doxycycline with time-kill studies and determinations of MICs and MBCs. Additionally, time-kill studies were performed to evaluate the activity of tigecycline in combination with vancomycin, gentamicin, rifampin, and doxycycline. Tigecycline alone actively inhibited the bacterial inoculums of all the tested strains. None of the other antibiotics exhibited enhanced killing activity, when combined with tigecycline, against vancomycin-resistant Enterococcus faecium. The tigecycline and gentamicin combination, however, did show some improved effects. The combination of tigecycline and gentamicin gave enhanced activity against the three Staphylococcus aureus isolates [39].

\section{Gram-negative bacteria}

One hundred medical centers from 25 countries located throughout the world contributed 2,240 clinical isolates of Enterobactereriaceae and selected non-fermentative Gramnegative bacilli for evaluation. The Enterobactereriaceae were found to be highly susceptible to tigecycline, including those organisms that produced extended spectrum beta-lactamases. The tigecycline $\mathrm{MIC}_{90}$ was $1 \mu \mathrm{g} / \mathrm{mL}$, and $99.4 \%$ of the isolates were susceptible to tigecycline at $\leq 4 \mu \mathrm{g} / \mathrm{mL}$. Diminished activity was recorded against Proteus mirabilis and indole-positive Proteus species. Tigecycline activity was very limited against Pseudomonas aeruginosa (16\% susceptibility). Tigecycline exhibited very good activity when tested against other nonfermentative Gram-negative bacilli, including Acinetobacter species $(96.1 \%$ susceptibility at $\leq 4 \mu \mathrm{g} / \mathrm{mL})$, and Stenotrophomonas maltophilia (100\% susceptibility) [40]. 
Between October 1997 and June 2002, 7,566 unique patient respiratory tract isolates of Haemophilus influenzae and 2,314 unique isolates of Moraxella catarrhalis were collected from 25 medical centers in Canada; $22.5 \%$ of the Haemophilus influenzae isolates and $92.4 \%$ of the Moraxella catarrhalis isolates produced beta-lactamase. The $\mathrm{MIC}_{90}$ against all isolates for tigecycline was $4 \mu \mathrm{g} / \mathrm{mL}$ (range of $\leq 0.06 \mu \mathrm{g} / \mathrm{mL}$ to $\geq 8 \mu \mathrm{g} / \mathrm{mL}$ ) [41]. In another study, tigecycline activity was evaluated on a worldwide collection of 1,215 strains of Haemophilus influenzae, 495 strains of Moraxella catarrhalis and 17 strains of Neisseria meningitidis. Tigecycline was uniformly active against all of the isolates, including those strains producing beta-lactamase [42].

From 1997 to 2000, 195 isolates of Stenotrophomonas maltophilia were collected in the Hospital Clínico San Carlos in Spain. All of the isolates were susceptible to minocycline, and $98 \%$ were susceptible to trimethoprim-sulfamethoxazole. Tigecycyline was found to be an active agent, with MICs that were three to four dilutions lower than tetracycline and two dilutions higher than minocycline. Tigecycline was found to inhibit $94.4 \%$ of the isolates when tested at $4 \mu \mathrm{g} / \mathrm{mL}$. Tigecycline activity was greater than those of amikacin, ceftazidime and ticarcillin-clavulanate [43].

In another survey, susceptibility testing was performed on 595 Acinetobacter isolates collected in the United Kingdom in 2000 from 52 sentinel clinical laboratories. Carbapenems, colistin, sulbactam, minocycline and tigecycline exhibited activity against greater than $80 \%$ of the isolates, while widespread resistance to cephalosporins, aminoglycosides and ciprofloxacin was noted. In the tetracycline class of antibiotics, the most active agent was minocycline, followed by tigecycline and then tetracycline. Both tigecycline and minocycline were noted to be able to overcome most bacterial resistance mechanisms operative in the Acinetobacter isolates [44].

The activities of tigecycline and other antibiotics were studied with 90 isolates of Eikenella corrodens collected in Madrid, Spain. Tigecycline inhibited all of the isolates at concentrations between $\leq 0.06$ and $4 \mu \mathrm{g} / \mathrm{mL}$, with an $\mathrm{MIC}_{90}=2$ $\mu \mathrm{g} / \mathrm{mL}$. Other $\mathrm{MIC}_{90} \mathrm{~s}$ were $1, \leq 0.5 / 0.25,0.5, \leq 0.12, \leq 2$, and 0.5 $\mu \mathrm{g} / \mathrm{mL}$ for ampicillin, amoxicillin-clavulanate, cefotaxime, imipenem, chloramphenicol, and ciprofloxacin, respectively [45].

\section{Anaerobic bacteria}

Tigecycline's in vitro activity against anaerobes was evaluated with 831 isolates comprising all of the species within the Bacteroides fragilis group. The bacteria were collected from various geographically diverse United States medical institutions from 1998 to 2000. Tigecycline was found to be more active than clindamycin, minocycline, trovafloxacin and cefoxitin, and less active than imipenem or piperacillintazobactam against all isolates when a breakpoint of $8 \mu \mathrm{g} / \mathrm{mL}$ was used to evaluate tigecycline activity [46].
In another study, 327 clinical anaerobic bacterial isolates submitted to Huddinge University Hospital, Sweden in 1998, were collected. Using a breakpoint of $4 \mu \mathrm{g} / \mathrm{mL}$, all of the peptostreptococci (Peptostreptococcus anaerobius, Peptostreptococcus asaccharolyticus, Peptostreptococcus micros, Peptostreptococcus magnus, Peptostreptococcus prevotii and Peptostreptococcus indolicus) were found to be susceptible to tigecycline. Additionally, tigecycline had uniform in vitro activity against all of the tested isolates of Clostridium perfringens, Clostridium difficile, Prevotella species, Propionibacterium acnes and Fusobacterium nucleatum. Most Bacteroides fragilis group strains (Bacteroides thetaiotaomicron, Bacteroides vulgatus, Bacteroides ovatus, Bacteroides uniformis, Bacteroides distasonis and Bacteroides fragilis) were susceptible to tigecycline; however, for the 67 strains of Bacteroides fragilis, the $\mathrm{MIC}$ range was 0.064 to $16 \mu \mathrm{g} / \mathrm{mL}$, with an $\mathrm{MIC}_{90}$ of $0.5 \mu \mathrm{g} /$ $\mathrm{mL}[47]$.

\section{Atypical organisms}

The susceptibilities of Mycoplasma hominis, Mycoplasma pneumoniae and Ureaplasma urealyticum were determined by agar dilution in an in vitro study of atypical organisms. Tigecycline was more active than tetracycline or minocycline when tested against 30 isolates of Mycoplasma pneumoniae (tigecycline $\mathrm{MIC}_{90}=0.25 \mu \mathrm{g} / \mathrm{mL}$ ). Twenty-nine isolates of Mycoplasma hominis were also susceptible to tigecycline, with an $\mathrm{MIC}_{90}$ of $0.5 \mu \mathrm{g} / \mathrm{mL}$. Ureaplasma urealyticum was less susceptible to tigecycline ( $\mathrm{MIC}_{90}=8 \mu \mathrm{g} / \mathrm{mL}$ for 25 isolates), when compared to tetracycline $\left(\mathrm{MIC}_{90}=1 \mu \mathrm{g} / \mathrm{mL}\right)$ and minocycline $\left(\mathrm{MIC}_{90}=0.25 \mu \mathrm{g} / \mathrm{mL}\right)$ [48].

The in vitro activities of tigecycline, tetracycline, doxycycline and minocycline were evaluated against rapidly and slowly growing mycobacteria. The 76 clinical specimens of rapidly growing mycobacteria were identified as Mycobacterium fortuitum group ( $\mathrm{n}=26)$, Mycobacterium abscessus $(\mathrm{n}=20)$, Mycobacterium chelonae $(\mathrm{n}=26)$, Mycobacterium immunogenum ( $\mathrm{n}=1)$ and the Mycobacterium smegmatis group ( $\mathrm{n}=1$ isolate each of Mycobacterium smegmatis sensu stricto, Mycobacterium wolinskyi and Mycobacterium goodie). The slowly growing mycobacteria consisted of five species of bacteria (Mycobacterium avium complex $(\mathrm{n}=11)$, Mycobacterium lentiflavum $(\mathrm{n}=10)$, Mycobacterium kansasii ( $\mathrm{n}=11)$, Mycobacterium marinum $(\mathrm{n}=11)$, Mycobacterium xenopi $(\mathrm{n}=1)$, and Mycobacterium simiae $(\mathrm{n}=1)$. Tigecycline was highly active against all of the rapidly growing mycobacterial isolates, with $\mathrm{MIC}_{90} \mathrm{~s}$ of 0.25 $\mu \mathrm{g} / \mathrm{mL}$ for Mycobacterium abscessus and $<0.12 \mu \mathrm{g} / \mathrm{mL}$ for Mycobacterium chelonae and the Mycobacterium fortuitum group. The tigecycline MICs were the same regardless of tetracycline activity and were 4- to 11-fold greater than those of the tetracyclines. No slowly growing nontuberculous mycobacteria were reported as susceptible to tigecycline. 
Minocycline was more active than tigecycline when tested against Mycobacterium marinum and Mycobacterium kansasii. The authors concluded that tigecycline has potential as a new agent to control the rapidly growing mycobacteria, especially Mycobacterium chelonae and Mycobacterium abscessus [49].

In another study, 37 isolates of Mycobacterium marinum from geographically diverse United States clinical laboratories were evaluated. Trimethoprim/sulfamethoxazole was the most active agent, with $91.9 \%$ of isolates determined to be susceptible. Tigecycline was reported to have an $\mathrm{MIC}_{90}$ of $3 \mu \mathrm{g} / \mathrm{mL}$, with the highest measured value found to be 24 $\mu \mathrm{g} / \mathrm{mL}$, which contrasts with an $\mathrm{MIC}_{90}$ of $2 \mu \mathrm{g} / \mathrm{mL}$ for minocycline [50].

\section{Animal Models}

The activity of tigecycline has been compared to vancomycin in experimental endocarditis in rats caused by vancomycin-susceptible and vancomycin-resistant Enterococcus faecalis, and by methicillin-resistant Staphylococcus aureus. In vitro, tigecycline was more active than vancomycin against these organisms. In this animal model, a catheter was placed across the aortic valve, with subsequent intravenous injection of bacteria 48 hours later, which lead to the development of endocarditis. Treatment with tigecycline or vancomycin was initiated 24 to 36 hours after bacterial injection. Tigecycline was noted to reduce bacterial vegetation titers by greater than $2 \log _{10}$ colony forming units when compared to untreated controls for both vancomycin-susceptible and vancomycin-resistant (VanA and VanB) Enterococcus faecalis strains. In addition, a reduction of more than $4 \log _{10}$ colony forming units of the methicillin-resistant Staphylococcus aureus isolate was reported. In this experimental model, tigecycline was more effective at reducing bacterial colony counts at a lower dose than vancomycin. This study revealed the therapeutic potential of tigecycline and the authors concluded that further investigations should be performed [51].

The in vivo protective effects of intravenous tigecycline were examined in an intraperitoneal mouse model, with acute lethal injections of Escherichia coli, Staphylococcus aureus, and Streptococcus pneumoniae isolates. Tigecycline showed protection against Staphylococcus aureus, including MRSA strains, and strains containing tet $(\mathrm{K})$ or tet $(\mathrm{M})$ resistance determinants. Median effective doses ranged from 0.79 to 2.3 $\mathrm{mg} / \mathrm{kg}$ of body weight. Against the Escherichia coli strains, tigecycline was active against those that were tetracyclinesensitive as well as those strains containing either tet(M) or the efflux determinant tet(A), tet(B), or tet(C), with median effective doses ranging from 1.5 to $3.5 \mathrm{mg} / \mathrm{kg}$. In this model, the in vivo efficacy results corresponded with the in vitro activity of tigecycline [23].

In a different study, also using a murine intraperitoneal infection model, both tigecycline and daptomycin demonstrated in vivo activity against glycopeptideintermediate Staphylococcus aureus, methicillin-resistant Staphylococcus aureus, and methicillin-susceptible Staphylococcus aureus strains. The median effective doses for tigecycline were $0.24 \mathrm{mg} / \mathrm{kg}$ body weight for the methicillinsusceptible Staphylococcus aureus strain, $0.72 \mathrm{mg} / \mathrm{kg}$ body weight for the methicillin-resistant Staphylococcus aureus strain and $1.9 \mathrm{mg} / \mathrm{kg}$ body weight for the glycopeptideintermediate Staphylococcus aureus strain. Tigecycline was noted to be more active than daptomycin against the glycopeptide-intermediate Staphylococcus aureus strain [38].

Additionally, three Enterococcus faecalis and four Enterococcus faecium isolates with differing susceptibilities to vancomycin and tetracyclines were studied in a mouse peritonitis model. Tigecycline was found to be very active against the isolates, as all the isolates were inhibited by $\leq 0.125 \mu \mathrm{g} / \mathrm{mL}$ of tigecycline. Even with a single subcutaneous dose, tigecycline exerted a protective effect against all of the tested strains, including those containing the Tet(M) tetracycline resistance determinant, and the VanA and VanB strains [52].

Tigecycline activity was investigated in vitro and in an experimental endocarditis animal model caused by injection of the susceptible Enterococcus faecalis JH2-2 strain, its VanA type transconjugant BM4316 and Enterococcus faecium HB217. Enterococcus faecium HB217 is a tetracyclineresistant, clinical VanA type strain. In the three study strains, tigecycline MICs were $0.06 \mu \mathrm{g} / \mathrm{mL}$. It was noted that tigecycline diffused in a homogenous manner into the vegetations, and there was a lower clearance of tigecycline from aortic vegetations than from the serum. The bacteriostatic activity of tigecycline was not changed by increasing concentrations of antibiotics to more than $1 \mu \mathrm{g} / \mathrm{mL}$ when evaluated by in vitro pharmacodynamic studies. A postantibiotic effect occurred that ranged from 1 to 4.5 hours at concentrations of 1 - to 20 -fold the MIC. In this rabbit model, the elimination half-life from the serum ranged from 3.3 to 3.6 hours. No resistance was elicited in the bacteria. Tigecycline performed well in this endocarditis model, exhibiting a prolonged half-life and postantibiotic effect, and homogenous penetration into vegetations [53].

The activity of tigecycline was evaluated in the prevention of death in a Legionnaires' disease guinea pig animal model. Tigecycline was found to be approximately as effective as erythromycin against intracellular Legionella pneumophila. Based on their findings, the authors of this study predicted that tigecycline would be effective for the treatment of mild Legionnaires' disease, but longer therapy (14 to 21 days) would be required for a cure, given the caveat that human pharmacokinetics are similar to guinea pig pharmacokinetics. Tigecycline, however, may not be the preferred drug for severe Legionnaires' disease, based on this animal data, especially for those patients that require hospitalization or are immunocompromised [54]. 
The efficacies of tigecycline and vancomycin, with and without rifampin, were compared in a rabbit model of osteomyelitis caused by methicillin-resistant Staphylococcus aureus. One group of rabbits was untreated, and the other groups received 28 days of antibiotic therapy, with treatment beginning two weeks after intramedullary injection of methicillinresistant Staphylococcus aureus. Animals that had received tigecycline and oral rifampin $(n=14)$ had a $100 \%$ clearance rate of the bacteria. Nine of 10 rabbits treated with tigecycline alone had bacterial clearance. Nine of 11 rabbits receiving vancomycin had clearance, while only four of 15 untreated controls had clearance. The authors stated that tigecycline appears to be an effective alternative to the use of vancomycin in the therapy of methicillin-resistant Staphylococcus aureus osteomyelitis [55].

Tigecycline, gentamicin, piperacillin, alone and in combination, were studied in a murine model of Pseudomonas aeruginosa pneumonia. Combined tigecycline and gentamicin lead to significantly greater reduction of colony counts of Pseudomonas aeruginosa, when compared to the use of either agent alone. No enhancement of activity was observed when piperacillin was combined with either tigecycline or gentamicin. No antagonism between combined antibiotics was reported with any of the combinations. The authors concluded that the combination of tigecycline and gentamicin has potential therapeutic value for the treatment of Pseudomonas aeruginosa pneumonia and that further studies are warranted [56].

Tigecycline and another experimental glycylcycline were studied in an experimental murine thigh infection model in neutropenic mice. After infection with various strains of bacteria, including Streptococcus pneumoniae, Staphylococcus aureus, Escherichia coli, and Klebsiella pneumoniae, therapy was initiated predominantly with a twicedaily dosing schedule. The results of this study were used to create a maximum-effect dose-response model that was used to determine the dose that produced a net bacteriostatic effect over 24 hours of therapy. Elimination half-lives of 1.05 to 2.34 hours and serum protein binding of $59 \%$ were noted for tigecycline. Similar activities were found against tetracyclinesensitive and tetracycline-resistant bacteria. In this model, the time that the antibiotic concentration remained above a certain multiple (range, 0.5 to 4 times) of the MIC appeared to be a better predictor of in vivo efficacy than $\mathrm{C}(\max )$ or AUC. These results suggested that to achieve $80 \%$ maximum efficacy, the concentration of unbound serum tigecycline should be maintained above the MIC for at least $50 \%$ of the time [57].

In another murine model with thigh and lung infections, the therapeutic efficacy of tigecycline was evaluated against methicillin-resistant and methicillin-susceptible Staphylococcus aureus, penicillin-resistant and penicillinsusceptible Streptococcus pneumoniae, Enterococcus faecium, vancomycin-resistant Enterococcus faecalis, Escherichia coli and Klebsiella pneumoniae. Effective static doses were determined; higher protective static doses were required for the infections caused by Gram-negative bacteria. The results of the study suggested excellent activity by tigecycline against a broad spectrum of organisms, including those exhibiting resistance to other antibiotics, in this murine thigh infection model. Tigecycline was found to be three-fold more active than vancomycin in the penicillin-resistant Streptococcus pneumoniae pneumonia model, and the authors concluded that tigecycline may be useful for Streptococcus pneumoniae pneumonia treatment [56].

Additionally, the activity of tigecycline was evaluated in vivo in a rabbit meningitis model with by a penicillin-resistant Streptococcus pneumoniae strain that was originally isolated from the cerebrospinal fluid of a patient with meningitis. Tigecycline was found to have a long half-life with the high single dose used in this model. Tigecycline exhibited bactericidal activity, with a 2 to $3 \log$ reduction in colony forming units per milliliter of cerebrospinal fluid. When vancomycin was given with tigecycline, greater clearance of the bacterial organisms was noted than that seen with either agent when administered alone. The authors concluded that tigecycline deserves further evaluation as a possible alternative antibiotic for the therapy of penicillin-resistant Streptococcus pneumoniae meningitis [58].

\section{Tigecycline and Pharmacokintics and Pharmacodynamics}

Tigecycline is only available as an injectable antibiotic and is administered twice daily as a one-hour infusion. Most studies evaluating the pharmacokinetics of tigecycline have used single dose administrations in normal volunteers. When a single $100 \mathrm{mg}$ intravenous dose was administered during one hour, the $\mathrm{C}_{\max }$ was $0.85-1 \mu \mathrm{g} / \mathrm{mL}$, the $\mathrm{AUC}_{0-\infty}$ was $4.2-5.8$ $\mu \mathrm{g} \bullet \mathrm{hr} / \mathrm{mL}$, and the half-life was 16 to 24 hours [59]. A linear dose response was observed for both the $\mathrm{C}_{\max }$ and $\mathrm{AUC}_{0-\infty}$ $(0.20 \pm 0.05 \mu \mathrm{g} / \mathrm{mL}$ to $1.52 \pm 0.16 \mu \mathrm{g} / \mathrm{mL}$ and $0.8 \pm 0.36 \mu \mathrm{g} \cdot \mathrm{hr} / \mathrm{mL}$ to $8.6 \pm 1.8 \mu \mathrm{g} \cdot \mathrm{hr} / \mathrm{mL}$ with 25 and $50 \mathrm{mg}$, respectively). In some studies, food or gender did not appear to significantly change the pharmacokinetics of tigecycline $[16,19,59,60]$.

A Phase I, randomized, double-blind, placebo-controlled, ascending single dose study was performed with healthy male subjects to evaluate the safety, tolerability and pharmacokinetics of tigecycline. In order to measure dose proportionality and the effect of food on tigecycline pharmacokinetics, eight male subjects received 12.5, 25, 50, $75,100,200$, and $300 \mathrm{mg}$ over one hour. In this randomized, double-blind study, the $\mathrm{C}_{\max }$ and $\mathrm{AUC}_{0-12}$ were linear, and ranged from $0.11-2.8 \mu \mathrm{g} / \mathrm{mL}$ and $0.9-17.9 \mu \mathrm{g} \bullet \mathrm{hr} / \mathrm{mL}$, respectively. Food was reported to improve the tolerability of tigecycline, while not changing tigecycline's pharmacokinetic profile. The maximum tolerated dose during fasting was 100 $\mathrm{mg}$, versus $200 \mathrm{mg}$ when subjects were fed [61].

In a multicenter, prospective, open-label trial of therapy of complicated skin and skin structure infections, the effects of multiple dosing of tigecycline were also evaluated. For patients 
receiving $25 \mathrm{mg}$ of tigecycline, the mean (SD) values for $\mathrm{C}_{\mathrm{ss} \text {,max }}$, area under the plasma concentration-time curve at steady state from 0 to 12 hours $\left(\mathrm{AUC}_{\mathrm{ss}, 0-12 \mathrm{~h}}\right)$, and with weight-adjusted systemic clearance, were found to be $0.265(0.206) \mu \mathrm{g} / \mathrm{mL}, 1.43$ $(0.668) \mu \mathrm{g} / \mathrm{mL} \cdot \mathrm{h}$ and $0.246(0.114) \mathrm{L} / \mathrm{kg} \cdot \mathrm{h}$, respectively. For those patients receiving $50 \mathrm{mg}$ of tigecycline, the $\mathrm{C}_{\mathrm{ss}, \max }, \mathrm{AUC}_{\mathrm{ss}, 0-12 \mathrm{~h}}$ and weight-adjusted systemic clearance were recorded as $0.403(0.182) \mu \mathrm{g} / \mathrm{mL}, 2.24(0.894) \mu \mathrm{g} / \mathrm{mL} \cdot \mathrm{h}$, and $0.310(0.124) \mathrm{L} /$ $\mathrm{kg} \cdot \mathrm{h}$, respectively [21].

Tigecycline has a large and variable volume of distribution that has been found to range from approximately 5 to over 10 $\mathrm{L} / \mathrm{kg}$ [59-61]. This is significantly greater than what has been measured with currently available tetracyclines [19]. The volume of distribution of tigecycline has been reported to be dose proportional, from $4.4 \pm 0.9 \mathrm{~L} / \mathrm{kg}$ with $25 \mathrm{mg}$ to $10.8 \pm 2.1$ $\mathrm{L} / \mathrm{kg}$ with a $150 \mathrm{mg}$ dose [16,59]. In addition, overall excellent tissue penetration was observed in a single dose study with rats. The highest levels of penetration were noted in the bone and bone marrow, followed by salivary gland, thyroid, spleen and kidney [62]. Cerebrospinal fluid concentrations of greater than $1 \mu \mathrm{g} / \mathrm{mL}$ at 3 hours that stayed at a steady state or increased at 6 hours were observed in a rabbit meningitis model, in which single doses of greater than $20 \mathrm{mg} / \mathrm{kg}$ of tigecycline were administered [58].

Tigecycline protein binding has been measured to be approximately $68 \%$. Tigecycline's half-life is 36 hours in humans. Less than $30 \%$ of tigecycline is excreted unchanged in the feces and urine, and tigecycline is metabolized primarily by liver glucuronidation. The $\mathrm{AUC}$ and $\mathrm{C}_{\max }$ of tigecycline are higher in patients with renal dysfunction; however, no dosage adjustments have been recommended. Currently, there is no data that establishes tigecycline pharmacokinetics and safety in patients with hepatic impairment or failure. It has been suggested that one should exercise caution with the use of this agent in patients with severe hepatic dysfunction, since most of the tigecycline is eliminated by the liver $[16,19,63]$.

In another pharmacokinetic study of tigecycline in healthy adult individuals and in volunteers with renal impairment, tigecycline exhibited approximate linear pharmacokinetics across all dose ranges. Tigecycline's long half-life, with a high volume of distribution, further suggested extensive tissue distribution. Within the study population, tigecycline pharmacokinetics was not altered by severe renal dysfunction or hemodialysis. Slight trends towards differences in tigecycline pharmacokinetics were noted, possibly due to age, gender or race. The authors stated, however, these differences should be further evaluated in larger populations [64].

Animal studies have suggested that the pharmacodynamic parameter that appears to best predict bacteriologic eradication is the time above the MIC $[19,57]$. In an in vitro pharmacodynamic infection model evaluating the activities of tigecycline, linezolid, quinupristin-dalfopristin, arbekacin, and daptomycin alone, and in combination, against two clinical strains of vancomycin-resistant Staphylococcus aureus, the combination of tigecycline and linezolid was reported to be the most potent [65].

Limited human data is available reporting adverse events associated with tigecycline administration or interactions with other administered drugs. Expanded numbers of patients are being enrolled in clinical trials, and existing data from a limited number of these trials suggest that tigecycline is generally well tolerated and safe to administer. The most frequentlyreported adverse events associated with tigecycline administration are nausea, vomiting and headache [19-21]. Experience with currently marketed tetracyclines may suggest other tigecycline effects, such as deposition in teeth and bone during calcification and drug interactions with antacids, anticoagulants and other agents [19].

\section{TIigecycline Clinical Trials}

Tigecycline has been evaluated in human Phase I and II clinical trials. Currently, tigecycline is being studied in patients with complicated skin and skin-structure infections, complicated intra-abdominal infections, and hospital and community-acquired pneumonias [16,20,21,66].

A Phase II, randomized, open-label study of complicated skin and skin-structure infections was performed in 14 centers in the United States between September 1999 and March 2001. Patients were administered 25 or $50 \mathrm{mg}$ tigecycline intravenously every 12 hours for 7 to 14 days. The clinical and microbiological efficacy, tolerability and pharmacokinetics of these two tigecycline doses were evaluated. The primary end point was the clinically observed cure rate for those patients who had completed the test-of-cure visit. The clinical cure rate at the end of therapy and the bacteriological response constituted the secondary end points. One hundred and sixty patients were administered at least one dose of tigecycline, of which 109 were clinically evaluable and 91 were microbiologically evaluable. For the test-of-cure visit, the clinical cure rate in the $25 \mathrm{mg}$ group was $67 \%$ (95\% CI, 53.3\% $-79.3 \%$ ) and $74 \%(95 \% \mathrm{CI}, 60.3 \%-85.0 \%)$ in the $50 \mathrm{mg}$ group. In the $25 \mathrm{mg}$ group, $56 \%(95 \% \mathrm{CI}, 40.0 \%-70.4 \%)$ of the patients had eradication of the pathogens versus $69 \%$ (95\% CI, $54.2 \%$ $-82.3 \%$ ) in the $50 \mathrm{mg}$ group. The most common adverse events were reported to be nausea and vomiting.

Additionally, in vitro tests evaluating susceptibility to tigecycline were performed with selected isolates from a clinical study for Streptococcus pyogenes, methicillinsusceptible and methicillin-resistant Staphylococcus aureus, Escherichia coli, Enterococcus faecalis, and Enterococcus faecium. All isolates had tigecycline $\mathrm{MIC}_{90} \mathrm{~s}$ from 0.06 to 0.50 $\mu \mathrm{g} / \mathrm{mL}$. In this study, tigecycline appeared efficacious and demonstrated a favorable pharmacokinetic profile for hospitalized patients with complicated skin and skin-structure infections [21].

The activity of tigecycline was also studied in a multicenter, Phase II, open-label study of patients with 
complicated intra-abdominal infections that required surgery. All patients were administered a loading dose of $100 \mathrm{mg}$ of tigecycline, followed by $50 \mathrm{mg}$ every 12 hours for 5 to 14 days. One hundred eleven patients with complicated cholecystitis, perforated and gangrenous appendicitis, or perforated diverticulitis and peritonitis, were enrolled into this study. Sixty-six patients were evaluated and all met the inclusion criteria. Cure rates at the test-of-cure visit and the end of treatment visit were reported as $67 \%$ (44 patients; $95 \% \mathrm{CI}$, $54.0 \%-77.8 \%$ ) and $76 \%$ (50 patients; $95 \%$ CI, 63.6\%-85.5\%), respectively. For the intent-to-treat analyses, the cure rate at the test-of-cure visit was 55\% (61/111 patients; $95 \% \mathrm{CI}, 45.2 \%$ $-64.45)$ and the end of treatment cure rate was $72 \%(80 / 111$ patients; $95 \%$ CI, $62.8 \%-80.2 \%$ ). The most common adverse events were reported to be nausea and vomiting. The authors concluded that tigecycline was safe and efficacious for patients with complicated intra-abdominal infections [20].

Based on the results of the above Phase II studies, tigecycline appears efficacious and well-tolerated. Phase III trials are currently underway to further evaluate the safety and efficacy of tigecycline $[16,20,21]$.

\section{Conclusions}

In summary, tigecycline, the first in a new class, the glycylcyclines, appears to hold significant promise as a new agent that can be added to our antimicrobial armamentarium to help overcome antibiotic resistance among clinically important bacteria. Tigecycline confers broad antibiotic coverage against vancomycin-resistant enterococci, methicillin-resistant Staphylococcus aureus and penicillinresistant Streptococcus pneumoniae. Additionally, against Gram-negative bacteria, tigecycline is highly active against many species that are multidrug-resistant, including those containing extended-spectrum beta-lactamases and Acinetobacter species, although resistance to tigecycline by Pseudomonas aeruginosa and reduced susceptibility among Proteus species have been noted. In human clinical Phase II trials, tigecycline has been reported to be efficacious and welltolerated, and Phase III trials are currently being performed to evaluate tigecycline in serious diseases, such as complicated skin and skin structure infections, complicated intra-abdominal infections and infections of the lower respiratory tract. It is anticipated that tigecycline's broad spectrum of activity will allow clinicians to use this new agent for empiric therapy of many serious infections, including those in which extensive antimicrobial resistance could be expected. Additionally, the potency of tigecycline may allow it to be used as a single agent in some clinical settings.

\section{Acknowledgements}

We thank Dr. Gisele Almeida Duboc of the HC-FMUSP for revision and bibliography support.

\section{References}

1. Bush K. Why It Is Important to Continue Antibacterial Drug Discovery. ASM News 2004;70:282-7.

2. Cazzola M., F. Blasi, S. Centanni, et al. Advances in the research and development of chemotherapeutic agents for respiratory tract bacterial infections. Pulm Pharmacol Ther 2001; $14: 367-81$.

3. Johnson A.P., D.M. Livermore, G.S. Tillotson. Antimicrobial susceptibility of Gram-positive bacteria: what's current, what's anticipated? J Hosp Infect 2001;49Suppl A:S3-11.

4. Jones R.N. Resistance patterns among nosocomial pathogens: trends over the past few years. Chest 2001;119:397S-404S.

5. Kang C.-I., S.-H. Kim, W. B. Park, et al. Bloodstream Infections Caused by Enterobacter Species: Predictors of 30-Day Mortality Rate and Impact of Broad-Spectrum Cephalosporin Resistance on Outcome. Clin Infect Dis 2004;39:812-8.

6. Shales D.M., S.J. Projan, J.E. Edwards. Antibiotic Discovery: State of the State. ASM News 2004;70:275-81.

7. Melzer M., S.J. Eykyn, W.R. Gransden, S. Chinn. Is methicillinresistant Staphylococcus aureus more virulent than methicillin-susceptible S. aureus? A comparative cohort study of British patients with nosocomial infection and bacteremia. Clin Infect Dis 2003;37:1453-60.

8. Leibovici L., I. Shraga, M. Drucker, et al. The benefit of appropriate empirical antibiotic treatment in patients with bloodstream infection. J Intern Med 1998;244:379-86.

9. Lodise T.P., P.S. McKinnon, L. Swiderski, M.J. Rybak. Outcomes analysis of delayed antibiotic treatment for hospital-acquired Staphylococcus aureus bacteremia. Clin Infect Dis 2003;36:1418-23.

10. Bouchillon S.K., B.M. Johnson, D.J. Hobana, et al. Determining incidence of extended spectrum beta-lactamase producing Enterobacteriaceae, vancomycin-resistant Enterococcus faecium and methicillin-resistant Staphylococcus aureus in 38 centres from 17 countries: the PEARLS study 2001-2002. Int J Antimicrob Agents 2004;24:119-24.

11. Hiramatsu K. Vancomycin-resistant Staphylococcus aureus: a new model of antibiotic resistance. Lancet Infect Dis 2001; $1: 147-55$.

12. Hiramatsu K., K. Okuma, X.X. Ma, et al. New trends in Staphylococcus aureus infections: glycopeptide resistance in hospital and methicillin resistance in the community. Curr Opin Infect Dis 2002;15:407-13.

13. Biedenbach D.J., M.L. Beach, R.N. Jones. In vitro antimicrobial activity of GAR-936 tested against antibiotic-resistant Grampositive blood stream infection isolates and strains producing extended-spectrum beta-lactamases. Diagn Microbiol Infect Dis 2001;40:173-7.

14. Gales A.C. Antimicrobial activity and spectrum of the new glycylcycline, GAR-936 tested against 1,203 recent clinical bacterial isolates. Diagn Microbiol Infect Dis 2000;36:19-36.

15. Jones R.N. Disk diffusion susceptibility test development for the new glycylcycline, GAR-936. Diagn Microbiol Infect Dis 1999; $35: 249-52$.

16. Reese A.M., D.S. Burgess. Tigecycline: A new glycylcycline antimicrobial. For submission [2006]. 
17. Bauer, G., C. Berens, S.J. Projan, W. Hillen. Comparison of tetracycline and tigecycline binding to ribosomes mapped by dimethylsulphate and drug-directed $\mathrm{Fe}^{2+}$ cleavage of $16 \mathrm{~S}$ rRNA. J Antimicrob Chemother 2004;53:592-9.

18. Chopra I. Glycylcyclines: third-generation tetracycline antibiotics. Curr Opin Pharmacol 2001;1:464-9.

19. Zhanel G.G., K. Homenuik, K. Nichol, et al. The glycylcyclines: a comparative review with the tetracyclines. Drugs 2004; 64:63-88.

20. Murray J., S. Wilson, S. Klein, et al. Presented at the 43rd Interscience Conference on Antimicrobial Agents and Chemotherapy, Chicago, Illinois, 2003.

21. Postier R.G., S.L. Green, S.R. Klein, et al. Results of a multicenter, randomized, open-label efficacy and safety study of two doses of tigecycline for complicated skin and skin-structure infections in hospitalized patients. Clin Ther 2004;26:704-14.

22. Connell S.R., D.M. Tracz, K.H. Nierhaus, D.E. Taylor. Ribosomal protection proteins and their mechanism of tetracycline resistance. Antimicrob Agents Chemother 2003; 47:3675-81.

23. Petersen P.J., N.V. Jacobus, W.J. Weiss, et al. In vitro and in vivo antibacterial activities of a novel glycylcycline, the 9-tbutylglycylamido derivative of minocycline (GAR-936). Antimicrob Agents Chemother 1999;43:738-44.

24. Projan S.J. Preclinical pharmacology of GAR-936, a novel glycylcycline antibacterial agent. Pharmacotherapy 2000;20:219S-23S.

25. Hirata T., A. Saito, K. Nishino, et al. Effects of efflux transporter genes on susceptibility of Escherichia coli to tigecycline (GAR936). Antimicrob Agents Chemother 2004;48:2179-84.

26. Fritsche T.R., J.T. Kirby, R.N. Jones. In vitro activity of tigecycline (GAR-936) tested against 11,859 recent clinical isolates associated with community-acquired respiratory tract and Gram-positive cutaneous infections. Diagn Microbiol Infect Dis 2004;49:201-9.

27. Reynolds R., N. Potz, M. Colman, et al. Antimicrobial susceptibility of the pathogens of bacteraemia in the UK and Ireland 2001-2002: the BSAC Bacteraemia Resistance Surveillance Programme. J Antimicrob Chemother 2004;53:1018-32.

28. Betriu C., I. Rodriguez-Avial, B.A. Sanchez, et al. In vitro activities of tigecycline (GAR-936) against recently isolated clinical bacteria in Spain. Antimicrob Agents Chemother 2002; 46:892-5.

29. Goldstein E.J., D.M. Citron, C.V. Merriam, et al. Comparative in vitro activities of GAR-936 against aerobic and anaerobic animal and human bite wound pathogens. Antimicrob Agents Chemother 2000;44:2747-51.

30. Cercenado E., S. Cercenado, J.A. Gomez, E. Bouza. In vitro activity of tigecycline (GAR-936), a novel glycylcycline, against vancomycin-resistant enterococci and staphylococci with diminished susceptibility to glycopeptides. J Antimicrob Chemother 2003;52:138-9.

31. Low D.E., B.N. Kreiswirth, K. Weiss, B.M. Willey. Activity of GAR-936 and other antimicrobial agents against North American isolates of Staphylococcus aureus. Int J Antimicrob Agents 2002;20:220-2.

32. Boucher H.W., C.B. Wennersten, G.M. Eliopoulos. In vitro activities of the glycylcycline GAR-936 against Gram-positive bacteria. Antimicrob Agents Chemother 2000;44:2225-9.
33. Kitzis M.D., A. Ly, F.W. Goldstein. In vitro activities of tigecycline (GAR-936) against multidrug-resistant Staphylococcus aureus and Streptococcus pneumoniae. Antimicrob Agents Chemother 2004;48:366-7.

34. Hoellman D.B., G.A. Pankuch, M.R. Jacobs, P.C. Appelbaum. Antipneumococcal activities of GAR-936 (a new glycylcycline) compared to those of nine other agents against penicillin-susceptible and -resistant pneumococci. Antimicrob Agents Chemother 2000;44:1085-8.

35. Zhanel G.G., L. Palatnick, K.A. Nichol, et al. Antimicrobial resistance in respiratory tract Streptococcus pneumoniae isolates: results of the Canadian Respiratory Organism Susceptibility Study, 1997 to 2002. Antimicrob Agents Chemother 2003;47:1867-74.

36. Betriu C., E. Culebras, I. Rodriguez-Avial, et al. In vitro activities of tigecycline against erythromycin-resistant Streptococcus pyogenes and Streptococcus agalactiae: mechanisms of macrolide and tetracycline resistance. Antimicrob Agents Chemother 2004;48:323-5.

37. Patel R., M.S. Rouse, K.E. Piper, J.M. Steckelberg. In vitro activity of GAR-936 against vancomycin-resistant enterococci, methicillin-resistant Staphylococcus aureus and penicillin-resistant Streptococcus pneumoniae. Diagn Microbiol Infect Dis 2000;38:177-9.

38. Petersen P.J., P.A. Bradford, W.J. Weiss, et al. In vitro and in vivo activities of tigecycline (GAR-936), daptomycin, and comparative antimicrobial agents against glycopeptideintermediate Staphylococcus aureus and other resistant Grampositive pathogens. Antimicrob Agents Chemother 2002;46:2595-601.

39. Mercier R.C., C. Kennedy, C. Meadows. Antimicrobial activity of tigecycline (GAR-936) against Enterococcus faecium and Staphylococcus aureus used alone and in combination. Pharmacotherapy 2002;22:1517-23.

40. Jones R., T. Fritsche H. Sader, M. Beach. Presented at the European Congress of Clinical Microbiology and Infectious Diseases, Prague, Czech Republic, 2004.

41. Zhanel G.G., L. Palatnick, K.A. Nichol, et al. Antimicrobial resistance in Haemophilus influenzae and Moraxella catarrhalis respiratory tract isolates: results of the Canadian Respiratory Organism Susceptibility Study, 1997 to 2002. Antimicrob Agents Chemother 2003;47:1875-81.

42. Sader H.S., T.R. Fritsche, J.T. Kirby, R.N. Jones. Presented at the European Congress of Clinical Microbiology and Infectious Diseases, Prague, Czech Republic, 2004.

43. Betriu C., I. Rodriguez-Avial, B.A. Sanchez, et al. Comparative in vitro activities of tigecycline (GAR-936) and other antimicrobial agents against Stenotrophomonas maltophilia. J Antimicrob Chemother 2002;50:758-9.

44. Henwood C.J., T. Gatward, M. Warner, et al. Antibiotic resistance among clinical isolates of Acinetobacter in the UK, and in vitro evaluation of tigecycline (GAR-936). J Antimicrob Chemother 2002;49:479-87.

45. Cercenado E., S. Cercenado, E. Bouza. In vitro activities of tigecycline (GAR-936) and 12 other antimicrobial agents against 90 Eikenella corrodens clinical isolates. Antimicrob Agents Chemother 2003;47:2644-5.

46. Jacobus N.V., L.A. McDermott, R. Ruthazer, D.R. Snydman. In vitro activities of tigecycline against the Bacteroides fragilis group. Antimicrob Agents Chemother 2004;48:1034-6. 
47. Edlund C., C.E. Nord. In vitro susceptibility of anaerobic bacteria to GAR-936, a new glycylcycline. Clin Microbiol Infect 2000;6:159-63.

48. Kenny G.E., F.D. Cartwright. Susceptibilities of Mycoplasma hominis, M. pneumoniae, and Ureaplasma urealyticum to GAR-936, dalfopristin, dirithromycin, evernimicin, gatifloxacin, linezolid, moxifloxacin, quinupristin-dalfopristin, and telithromycin compared to their susceptibilities to reference macrolides, tetracyclines, and quinolones. Antimicrob Agents Chemother 2001; $45: 2604-8$.

49. Wallace R.J., Jr., B.A. Brown-Elliott, C.J. Crist, et al. Comparison of the in vitro activity of the glycylcycline tigecycline (formerly GAR-936) with those of tetracycline, minocycline, and doxycycline against isolates of nontuberculous mycobacteria. Antimicrob Agents Chemother 2002;46:3164-7.

50. Rhomberg P.R., R.N. Jones. In vitro activity of 11 antimicrobial agents, including gatifloxacin and GAR936, tested against clinical isolates of Mycobacterium marinum. Diagn Microbiol Infect Dis 2002;42:145-7.

51. Murphy T.M., J.M. Deitz, P.J. Petersen, et al. Therapeutic efficacy of GAR-936, a novel glycylcycline, in a rat model of experimental endocarditis. Antimicrob Agents Chemother 2000;44:3022-7.

52. Nannini E.C., S.R. Pai, K.V. Singh, B.E. Murray. Activity of tigecycline (GAR-936), a novel glycylcycline, against Enterococci in the mouse peritonitis model. Antimicrob Agents Chemother 2003;47:529-32.

53. Lefort A., M. Lafaurie, L. Massias, et al. Activity and diffusion of tigecycline (GAR-936) in experimental enterococcal endocarditis. Antimicrob Agents Chemother 2003;47:216-22.

54. Edelstein P.H., W.J. Weiss, M.A. Edelstein. Activities of tigecycline (GAR-936) against Legionella pneumophila in vitro and in guinea pigs with $L$. pneumophila pneumonia. Antimicrob Agents Chemother 2003;47:533-40.

55. Yin L., L. Lazzarini, S. Bortolo, et al. Presented at the 41st Annual Meeting of IDSA, San Diego, California, 2003.
56. Mikels S.M., A.S. Brown, L. Breden, et al. Presented at the 39th Interscience Conference on Antimicrobial Agents and Chemotherapy, San Francisco, CA, 1999.

57. van Ogtrop M.L., D. Andes, T.J. Stamstad, et al. In vivo pharmacodynamic activities of two glycylcyclines (GAR936 and WAY 152,288) against various Gram-positive and Gram-negative bacteria. Antimicrob Agents Chemother 2000;44:943-9.

58. Fang G.D., W.J. Weiss, W. M. Scheld. Presented at the 40th Interscience Conference on Antimicrobial Agents and Chemotherapy, Toronto, Canada, 2000.

59. Sesoko S., K. Umemura, M. Nakashima. Presented at the 42nd Interscience Conference on Antimicrobial Agents and Chemotherapy, San Diego, California, 2002.

60. Muralidharan G., P. Mojaverian, M. Micalizzi, et al. Presented at the 40th Interscience Conference on Antimicrobial Agents and Chemotherapy, Toronto, Canada, 2000.

61. Muralidharan G., J. Getsy, P. Mayer, et al. Presented at the 39th Interscience Conference on Antimicrobial Agents and Chemotherapy, San Francisco, CA, 1999.

62. Tombs N.L. Presented at the 39th Interscience Conference on Antimicrobial Agents and Chemotherapy, San Francisco, CA, 1999.

63. Troy S.M., G. Muralidharan, M. Micalizzi, et al. Presented at the 43rd Interscience Conference on Antimicrobial Agents and Chemotherapy, Chicago, Illinois, 2003.

64. Meagher A.K., B.B. Cirincione K.A. Liolios, et al. Presented at the European Congress of Clinical Microbiology and Infectious Diseases, Prague, Czech Republic, 2004.

65. Huang V., W.J. Brown, M.J. Rybak. Presented at the European Congress of Clinical Microbiology and Infectious Diseases, Prague, Czech Republic, 2004.

66. Postier R., S. Klein, S. Green, E. Loh. Presented at the 43rd Interscience Conference on Antimicrobial Agents and Chemotherapy, Chicago, Illinois, 2003. 